
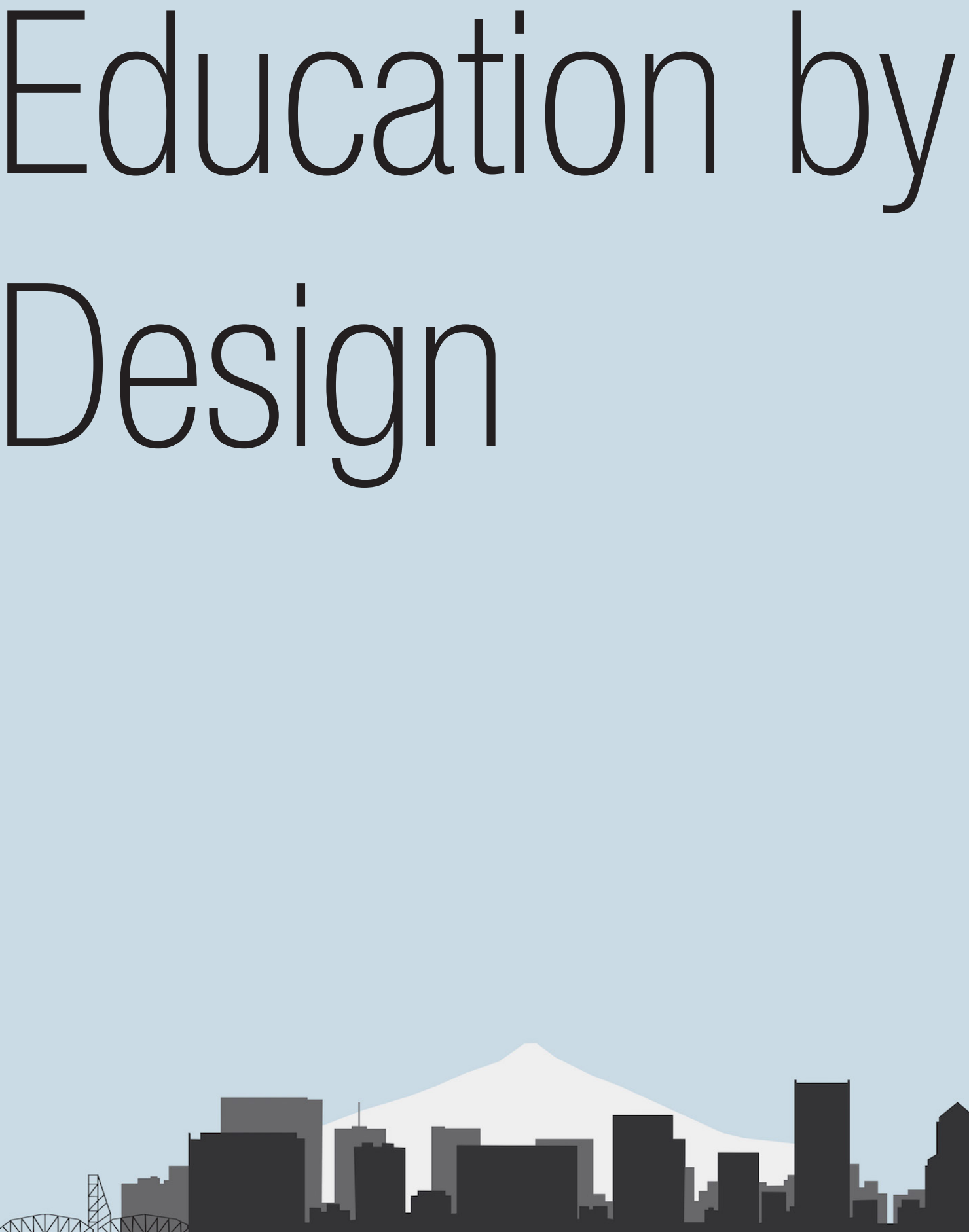

2019 Reynolds Symposium: Education by Design October 18-20, 2019 


\section{Organizing Committee:}

[co-organizers]

Professor Alison Kwok, Ph.D, FAIA, University of Oregon

Emeritus Professor John Reynolds, FAIA, University of Oregon

\section{[Symposium coordinator]}

Isabel Rivera, Ph.D., University of Oregon

Professor Walter Grondzik, P.E., Ball State University

Professor Bruce Haglund, AIA Assoc., University of Idaho

Assistant Professor Emily McGlohn, AIA, Auburn University

Associate Professor Ulrike Passe, lowa State University

Assistant Professor Siobhan Rockcastle, Ph.D., University of Oregon

Sharon Refvem, FAIA, LEED Fellow, Senior Associate and Director, Sustainability Resource Group, Hawley Peterson Snyder 


\title{
A BIM-enabled pedagogical approach
}

\author{
Ming $\mathrm{Hu}$, AIA \\ Assistant Professor \\ University of Maryland \\ College Park, Maryland \\ mhu2008@umd.edu
}

\begin{abstract}
Educators and practitioners have come to the consensus that Building Information Modeling (BIM) has radically transformed how the architecture, engineering, and construction (AEC) industry practices and operates. The move from using traditional Drafting-based Modeling(DM) to BIM constitutes a new methodology rather than the simple introduction of a new tool. BIM has already become mainstream in practice. But there is limited number of publications that addressed how this critical development can be used effectively in higher education. The critical research goal of this study is to document a method of using BIM as an effective pedagogy to teach a large, mixed- level technology course. A BIM-enabled pedagogy (BEP) was developed and tested in a "Building Materials and Construction Methods" (BMCM) class to compare with traditional Drafting-based Modeling pedagogy (DMP). The preliminary results demonstrated that BEP is more effective than DMP for teaching technology courses in an architecture curriculum. The aims of this research are as follows: 1) introduce an integrated, BIM-enabled pedagogy in the BMCM course; 2) identify applicable BIM-based techniques useful in architectural education; and 3) present some interesting findings regarding the effectiveness of this pedagogy for students at different levels. In the end, the pedagogical approach is discussed, and further research tasks are identified.
\end{abstract}

\section{INTRODUCTION}

Design education and technology education continue to be viewed as the separate domain of learning, separated by pedagogical gaps and teaching tradition, and such separation has been reflected in most curriculum (Doyle et al. 2016). In most architecture programs, technology courses are taught separately from the studio, technology courses are typically taught in a lecture setting with the instructor to student ratio of 1:60-140, in the studio the instructor and studio ratio is 1:10-12. This difference reflects and leads to different teaching pedagogy, teaching techniques, learning outcome evaluation and teacher- student interaction. Historically, students find it is difficult to translate the technological knowledge learned in the lecture to design process, meanwhile, technology courses are viewed as less motivating and interesting.

The Building Materials and Construction Methods (BMCM) course is a foundational and required technology course for most accredited architectural curriculums, construction management curriculums, and engineering programs. It has been traditionally taught in lecture settings. In addressing the changed building design and construction technologies, many programs have tried various methods for integrating emerging technologies into their curricula, such as variety Drafting-based Modeling design and documentation tools including Autodesk Revit. BIM is a complex design and construction technology and methodology that has been adopted widely by industry. But, BIM has not been widely adopted as a pedagogical method in AEC-related curriculums yet.

This research compares traditional Drafting-based Modeling pedagogy (DMP) to BIM-enable pedagogy (BEP) in technology courses in architecture program to evaluate the effectiveness of the proposed pedagogy. Within the existing architecture programs in United States that integrate DMP, most courses are computer courses focusing on Drafting-based Modeling technical skills or project-based design courses that use computer programs as modeling or representation tools. Very rarely it has been adopted in large lecture courses that cover a wide range of topics as a new pedagogical approach and teaching platform. DMP focuses on skills, topics and techniques, and BEP aims at providing a holistic and challenging learning platform by integrating traditional design thinking used in studio teaching in technology courses. Research showed DMP is less successful to lower level students because of the increased complexity may hinder students learning rather than help (Denzer 2008). In a BEP 
environment, BIM is incorporated as a process instead of a standalone tool or several standalone tools. DMP was applied in the first offering of BMCM (2016 fall semester) and BEP was tested in the second offering (2017 fall semester).

\section{The role of and challenges for BIM education in technology courses and studio}

Educators and practitioners have already built a consensus regarding how BIM has radically transformed the way the AEC industry practices and operates (Simon \& Hu 2017). The move from traditional CAD to BIM constitutes a new methodology rather than the simple introduction of a new tool (Denzer et al. 2008). In comparison to the industry transformation, the incursion of BIM seems to have encountered more obstacles in education. BIM is "parameter-defined" and "inherently answer-driven," while traditional design thinking is "question-driven" (Denzer et al. 2008). The new BIM approach could be seen by traditional studio teachers as a threat to critical design thinking. Therefore, the implementation of the BIM pedagogical shift needs to respect traditional design thinking to be successful. Previous experiments of BIM course had mixed results and showed not all attempts are successful.

The course taught at Montana State University was a 400-level construction documentation course. The instructor, Livingston thinks the placement of BIM-based investigation in technical courses addresses larger issues of architectural representation (Livingston 2008). BIM has been primarily used a tool to help students to gain a greater understanding of building materials and systems. Students are required to create a schematic design information model and then develop details illustrating materials and connections based on the initial model. The way in which BIM played an important role is through the formulation and construction of details that integrate into the larger information model, forming a critical relationship between the role of $2 \mathrm{D}$ and $3 \mathrm{D}$ information. However, they also documented that there was a disjunctive relationship between the details and overall project (Livingston 2008) as BIM approach was focusing on details instead of overall process.

The University of Wyoming tested the method using BIM in junior and senior studios for six semesters and reached several conclusions-for example, BIM prompts students to think about architecture, structure, and mechanical systems in an integrated manner and to consider issues of materiality and construction at an earlier stage of design compared to traditional 2D design (Denzer et al. 2008). They also observed that students using BIM often were able to develop more complicated designs since building in $3 \mathrm{D}$ helped them resolve problems earlier than when using 2D. The shortcoming is that BIM was once again used as a tool and students were not fully immersed in BIM environment as what is happening in the industry. According to Hedegs and Denzer's experiment, only fifty percent of students thought that BIM improved their understanding of how construction materials are assembled (Hedegs \& Denzer 2007). Based on previous study and program experiments, the challenge to using BIM as a pedagogical approach in technology courses include the followings: 1) a higher requirement for students' knowledge base and skill sets ((Hedegs \& Denzer 2007), 2) the disconnection from traditional studio training(Doyle \& Senske 2016)., and 3) the conflict between lecture setting and hands-on requirement of using BIM programs (Livingston 2008). In this research project, the focus is on challenge two and three, challenge one poses more significant curriculum questions that are needed for broader discussion.

\section{BEP COURSE DESIGN}

The course developed by the author is derived from a traditional BMCM lecture course that is a required course for the Bachelor of Art in Architecture, Bachelor of Science in Architecture, and Master of Architecture degrees. It is offered as a mixed graduate/undergraduate technical prerequisite course in an Architecture curriculum (refer to Figure 1). The course is designed for a large student body, around 108 to 120 , with a clear goal of not only teaching students fundamental knowledge about building materials and methods but also exposing students to BIM process and using BIM as a teaching platform to enhance and deepen their understanding. The assumption was that BIM-enable pedagogy (BEP) could provide a more challenge yet inviting learning environment so the students will be more self-motivated. And also, BEP could bridge the traditional gap exists in studio teaching and technology courses in architecture school. The course contents are divided into three integrated categories: 1) major building materials: wood, concrete, and steel; 2) major building assemblies: wall, roof, and other enclosure systems; and 3) 
integrated design thinking (construction methods and modern technology). One critical learning objectives for the students completing the course is to able to understand the complicated and multidisciplinary construction activity and the integrated process in the building industry, which is very different from traditional learning objective in BMCM courses. This outcome requires students not only to understand materials properties and construction methods, but also to establish a framework to understand the different players in the building industry. This has been a challenge for a large lecture course taught in a single-discipline school in a traditional education curriculum. Also this has been a constant struggle for architecture students with only one or two semesters years in school to comprehend such complicated and collaborative nature of design and construction procedures.

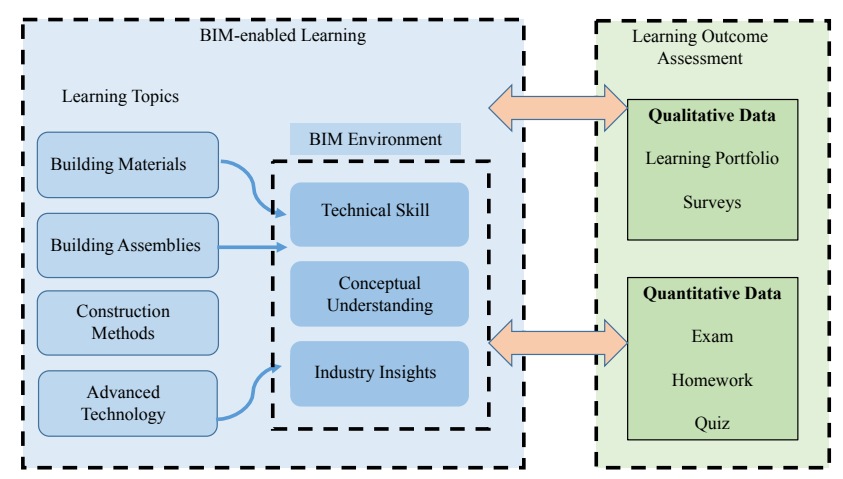

Figure 1. BIM-enabled pedagogy approach

This course had two offerings since 2016, in 2016 fall semester and 2017 fall semester. In the first offering, the instructor applied the convention Computed-aided pedagogy (DMP) of integrating Autodesk Revit in the core course as a stand-alone tool. And in the second offering a proposed BIM-enabled pedagogy (BEP) was created and tested to provide immerse BIM-enabled learning environment. In the BEP environment, BIM is used as a platform/process to help students understand and interweave the different pieces of knowledges and skills. A total of 118 students in Fall 2016 and 106 students in Fall 2017 enrolled in the class. The first student group (118 students) was used as a control and comparative group to assess the effectiveness of the new pedagogical approach. The second students' group included $4.6 \%$ freshmen, $59.4 \%$ sophomores, $14.2 \%$ juniors, $15.1 \%$ seniors, and $6.4 \%$ graduates. Of these, $51.9 \%$ were female students and $48.1 \%$ male students. And $58.5 \%$ knew nothing about BIM at the beginning of the class, $16 \%$ had never used a 3D program, and 33\% had learned Autodesk Revit to certain degree as a drafting tool in a community college or high school but never realized that Revit is one type of BIM software. Course assignments are organized into three different areas. First, BIM exercises are composed of modeling assignments and research components. Students are required to learn and model particular building components or assemblies that are covered intensively in lectures. Also, during the same period, they are required to conduct research on BIM use in the industry related to particular construction methods. Second, exams are composed of two parts: an in-class exam and a take-home portion. The takehome portions are observation assignments that ask students to observe a construction site or particular building materials on their own. The in-class exam tests their in-depth understanding of those topics. The third component is case studies and building tours (refer to Figure 1).

The BIM content was divided into three major parts: 1) what BIM is and what BIM can do in design and construction; 2) what building component/assembly is and how to use the "Revit family" to represent and simulate the materials and construction process; and 3) how to translate the knowledge about materials and constructions to their design projects, particularly brick and stone. The technical details of how to use the software were taught using in-class tutorials, exercises, assignments, and multiple outside-class workshops conducted by the instructor and three teaching assistants. Altogether, 24 hours (roughly 16 
hours of course time) of the workshop and in-class hours are offered to teach software. Beyond the workshops, students are required to enroll in the online comprehensive Revit tutorial offered by Linda.com. Altogether, 72 hours of online training are available to students on Linda at any time without charge.

\section{Evaluation Methodology}

This research project used a mixed method to evaluate students' learning outcome including a series of the online survey, student self-reports and course evaluations, student homework/test score were also compared and evaluated. The effectiveness of the proposed BEP is measured by four factors: 1) students' understanding of course topics/contents; 2) students' ability to connect construction knowledge to other courses (integration); 3) students' self-evaluation and competency building (critical thinking); 4) students' course evaluation (teachers' effectiveness). Assignments, graded homework, and exams were used to provide frequent assessments of students' learning outcomes. To answer the question of whether BEP is effective in a topic-based lecture course, the author designed an assessment framework to measure the learning results and students' progress through the entire semester. Since this is a large class with 118 in the first offering and 106 students in the second offering, the conclusion of this paper could provide a meaningful and helpful reference. The data generated by this research was a mix of qualitative and quantitative information. Quantitative data were from online surveys conducted after each major exam to collect students' self-assessments and feedback on the effectiveness of the BEP approach. Qualitative data were collected from students' course-learning portfolios and used to measure the students' selfassessments of their critical thinking skills. By overlaying quantitative and qualitative data, the author was able to find the trend and pattern and draw some preliminary conclusions. The measurements, values, and descriptive statics are discussed in findings and results. The software chosen to implement BIM was Revit due to its rich data and information on building materials and constructions.

\section{Sample assignments}

The second and third homework assignments have portions of modeling concrete floor systems and masonry walls. As shown in Figures 2 and 3, almost half of the students felt strongly about the knowledge gained in learning brick walls.

One-way solid slab with beams and girders
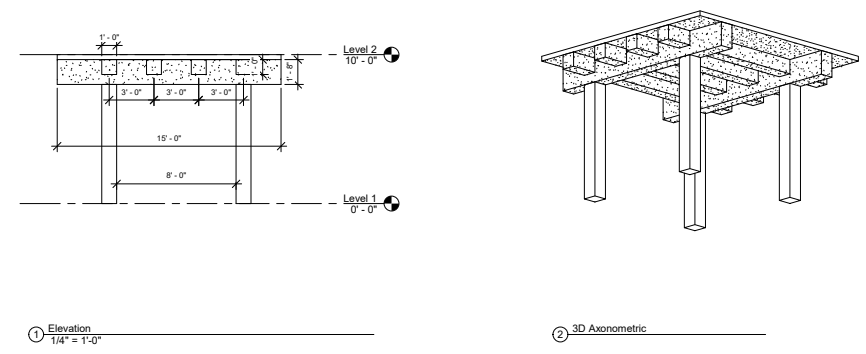

Figure 2. Homework 2 - Concrete
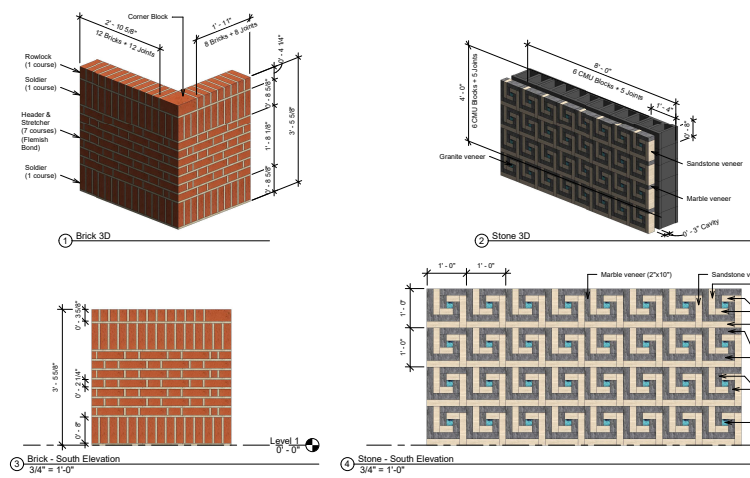

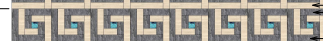


Figure 3. Homework 3 - Masonry Wall

\section{FINDINGS AND RESULTS}

\section{Does BEP deepen student's understanding of course contents?}

Five graded homework were given in each of the offering, and the assignments were similar in the way could be used as direct measurement to compare the effectiveness of BDP. The difference is that in the first offering students were asked to complete homework by hand drafting, and in the second offering students were asked to build BIM model, grading rubrics are the same in the two offerings. Figure 4 shows results of homework 2. In first offering (fall 2016), 32.5\% of students got 90-100 points, $13.3 \%$ of students got $80-90$ points, $8 \%$ of students got $70-80$ points, $6 \%$ of students got $60-70$ points, while $40 \%$ got lower than 60 points. In the second offering (fall 2017), $82.5 \%$ of students got $90-100$ points, $10.7 \%$ of students got $80-90$ points, $2.9 \%$ of students got $70-80$ points, $2 \%$ of students got $60-70$ points, while $2 \%$ got lower than 60 points. It shows clearly there was dramatic improvement of student score.

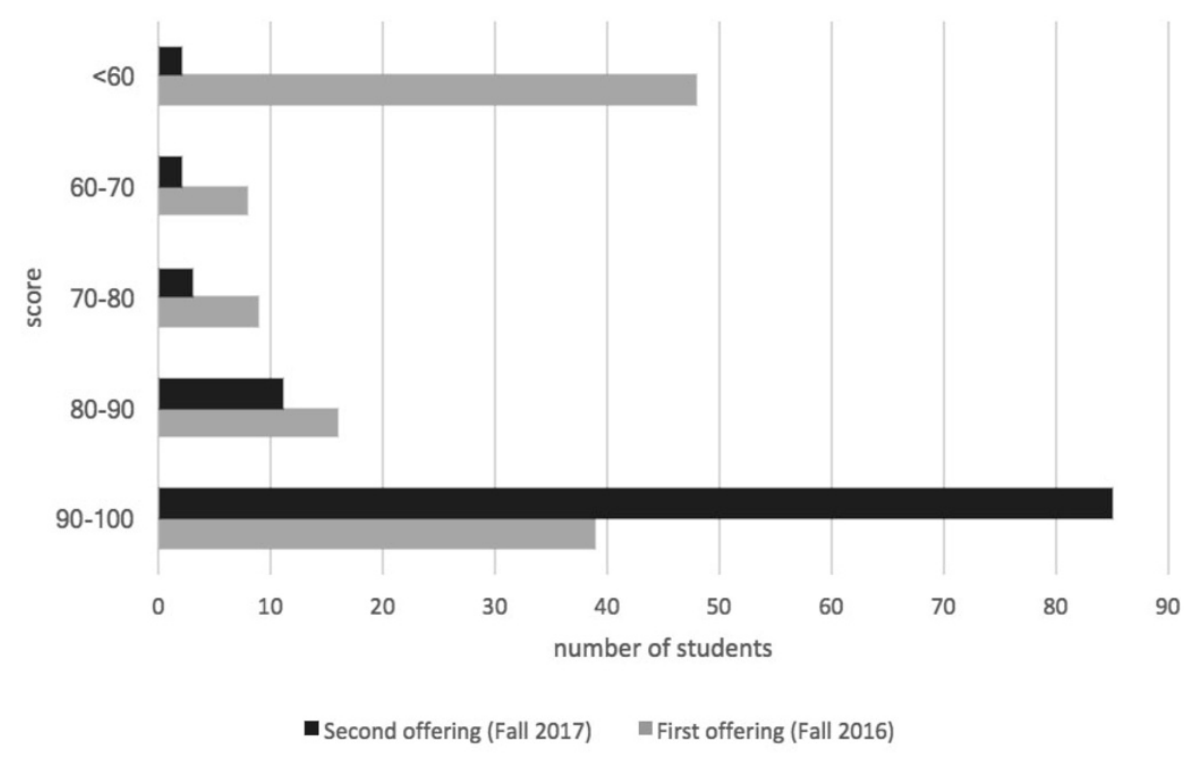

Figure 4 Homework 2 Grade comparison (x-axis represent the actual student numbers)

Figure 5 shows results of homework 3. In first offering (fall 2016), 55.8\% of students got 90-100 points, $20 \%$ of students got $80-90$ points, $5.8 \%$ of students got $70-80$ points, $1.7 \%$ of students got $60-70$ points, while $16.7 \%$ got lower than 60 points. In the second offering (fall 2017), 68.6\% of students got 90-100 points, $13.7 \%$ of students got $80-90$ points, $6.9 \%$ of students got $70-80$ points, $2.9 \%$ of students got $60-70$ points, while $7.8 \%$ got lower than 60 points. It shows clearly there was dramatic improvement of student score. The results also shows there were largely improvement of student grade, particularly the number of students who got lower than 6opoints has been decreased by close to $10 \%$. 


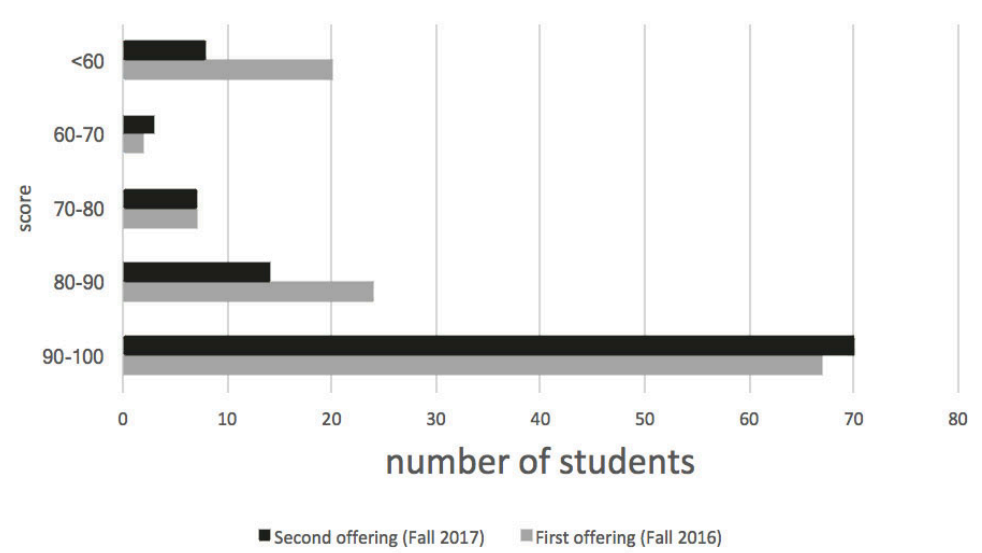

Figure 5 Homework 3 Grade comparison (x-axis represent the actual student numbers)

\section{Does BDP provides an effective learning environment?}

10 online surveys were conducted through the two semesters and the survey results showed BEP is very effective in compared to DMP: In first offering (fall 2016), 20\% of students agreed that "creating BIM models helped you to better understand architectural systems (wall, foundation, floor, roof, etc.) and 15\% strongly agreed; in the second offering (fall 2017), 35.5\% of students agreed and $22.9 \%$ strongly agreed. From 2016 to 2017, there was 23\% increase in effectiveness based on student self-report. The more dramatic change is the students' dissatisfaction rate: In the first offering (fall 2016), 25\% students found BDP was less effective and probably even hindered their learning and in the second offering only $9 \%$ student found BEP is not effective for them. (refer to Figure 6).

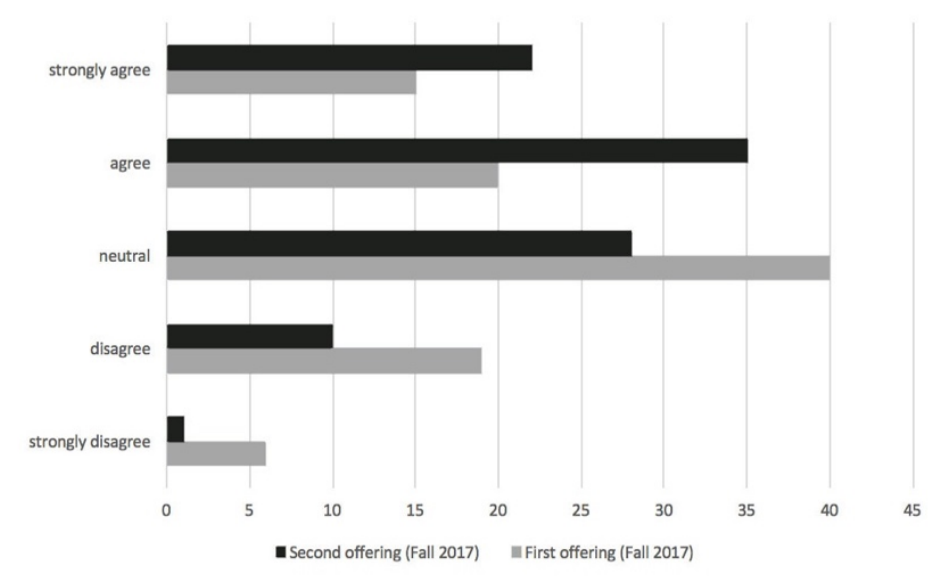

Figure 6 BIM's effectiveness (x-axis represent the actual student numbers)

Establishing the understanding of BIM in a qualitative way is the foundation of the BEP approach which set it apart from DMP. Overall, BIM is not an easy concept to grasp. In the second offering (2017), at the first half semester mark, after lectures, guest lectures, and multiple BIM lab sessions, the majority of students (36\%) felt neutral about the difficulty of learning BIM at a conceptual level. An equal number of students disagreed and agreed that the BIM concept is easy to understand (22.5\%), and $17 \%$ of students strongly disagreed that BIM concept is easy to understand (refer to Figure 9). It's been proven that grasping the BIM concept demands a more in-depth understanding of the building industry than typically provided in overall architectural curriculums since the current curriculum is heavily focusing on design thinking. The lack of preparedness of students was compensated for by self-guided research into this topic. Through several research assignments, a much larger portion of students started to grasp the BIM concept and understand the difference between BEP and DMP approach. 


\section{Does BEP promote integration between technology course and design studio?}

$\mathrm{BEP}$ is proven to be more effective to help students to comprehend the importance of technological integration in design and construction. Also BEP encourages visualize the different construction method and thinks about architecture from different perspectives. This is the type of soft technological skills and outlook is typically lacks in traditional DMP approach. In the DMP environment (first offering), since BIM software Revit was taught as stand-alone tool, by the end of 2016 semester, $39 \%$ students felt neutral about "BIM helps me to connect construction knowledge to design ideas", $36 \%$ students felt negative and only $25 \%$ students felt positive about BIM help them to link construction knowledge to other courses. In the BEP environment of 2017 semester, $78 \%$ students reported positive outcomes about "BIM helps me to connect construction knowledge to design ideas" and demonstrate the results in their final projects and course learning portfolio. (refer to Figure 7). This is the second effective impact of the BEP approach: help students on connecting technical information to design.

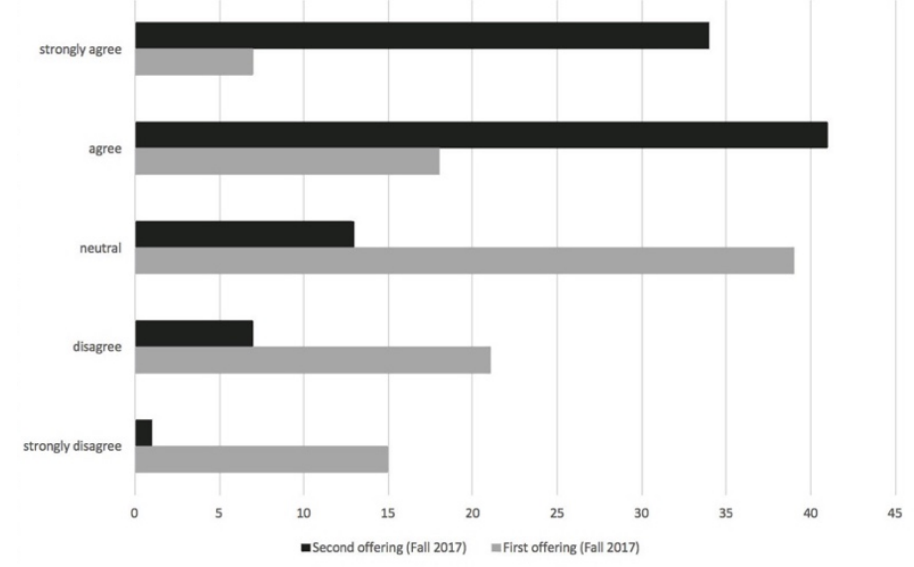

Figure 7 Students' ability to integrate technical knowledge in design (x-axis represent the actual student numbers)

Self-motivated learning and positive learning outcome could promote life-long learning habits. At the end of the 2017 fall semester, $36.4 \%$ of students strongly agreed that they "want to learn more about BIM," $39.4 \%$ agreed, and only $3 \%$ disagreed.

\section{CONCLUSION}

The survey studies showed that industry professionals believe that BIM concepts, collaborative implementation processes, and skills in BIM tools are critical and complementary to each other in practice and that these should be integrated into ACE core topics to achieve the best learning outcome (Abdirad and Dossick 2016). The current BIM implementation approaches have not addressed the systematic need to change the curriculum and create a pedagogical shift. In the past decade, different experimental BIM pedagogies have been implemented in AEC programs. Some programs developed new stand-alone BIM courses to cover the techniques of BIM use. Some programs modified existing core courses to integrate particular BIM topics. Previous studies suggest that offering stand-alone BIM courses without any follow-ups in other courses do not support student long-term learning because students rarely find an opportunity to re-use BIM skills in different courses (Ghosh and Chasey 2013; Clevenger et al. 2010; Abdirad and Dossick.2016). Updating existing course modules has had limited effect since BIM was used as a secondary technical tool, and the combination of the steep learning curve and limited course time hinders the effectiveness of the BIM pedagogy.

This paper shares the author's experiment of proposed BEP approach in a traditional large lecture course and to start a conversation on how technology course could be taught more effectively. The aim is to promote further discussion on and investigation of this important topic. The preliminary results from this large, mixed, lecture-based course indicated that BIM, when integrated as a teaching platform, provided a novel pedagogical approach for teaching technology courses such as BMCM. The project results provide very positive evidence of the effectiveness of using BEP approach. Also, students at the end of the semester indicated a pronounced preference for continuing to use this learning platform versus the more traditional DMP. The weakness of the past two offerings is that students were only exposed to a BIM authoring tool (Revit): they were not exposed to other BIM-related concepts, such as 4D modeling. The 
author is planning to integrate 4D modeling into a higher-level course (a graduate course) with a smaller class size.

Another limitation of this study is the limited sample size - two course offerings; one representing DMP and one representing BEP only provide the preliminary observations, it may be it may be premature to draw solid conclusion until a broader sample set including other DMP vs BEP courses, taught by different faculty, are recorded and assessed. However, The challenge is that, in order to effectively deliver course topics (material and methods) with this BEP approach, students are required to have had basic training in $3 \mathrm{D}$ programs in any kind of format. As the learning curve for most BIM programs is steeper than for conventional modeling programs, the BEP is more effective when students have had basic software training before taking the class, since the course focuses on building materials and methods instead of learning software. There are several barriers to promoting BEP in the existing program, one of which is that the National Architecture Accreditation Board (NAAB) does not require an architectural curriculum to offer such computation design/modeling training. This could partially explain why most BEP is currently used in a non-systematic way. However, without a systematic change, the full advantage and benefits of BEP cannot be realized.

\section{REFERENCES}

Abdirad, H., \& Dossick, C. S. (2016). BIM curriculum design in architecture, engineering, and construction education: a systematic review. Journal of Information Technology in Construction (ITcon), 21(17), 250-271.

Becerik-Gerber, B., Jazizadeh, F., Li, N., \& Calis, G. (2011). Application areas and data requirements for BIM-enabled facilities management. Journal of construction engineering and management, 138(3), 431-442.

Cheng, R. (2006a). "Suggestions for an Integrative Education," American Institute of Architects (AIA)

Cheng, R. (2006b). Questioning the role of BIM in architectural education. AECbytes Viewpoint, 26.

Construction, M. H. (2012). The business value of BIM in North America: multi-year trend analysis and user ratings (2007-2012). Smart Market Report.

Clevenger, C. M., Ozbek, M., Glick, S., \& Porter, D. (2010). Integrating BIM into construction management education. In EcoBuild Proceedings of the BIM-Related Academic Workshop.

Construction Conference: New Developments in Structural Engineering and Construction, ISEC 2013. Research Publishing Services.

Doyle, S., \& Senske, N. (2016). Between design and digital: bridging the gaps in architectural education.

Deutsch, R. (2011). BIM and integrated design: strategies for architectural practice. John Wiley \& Sons.

Report on Integrated Practice. http://www.aia.org/SiteObjects/files/5_Cheng.pdf, accessed March 1, 2008.

Denzer, A. S., \& Hedges, K. E. (2008). From CAD to BIM: Educational strategies for the coming paradigm shift. In AEI 2008: Building Integration Solutions (pp. 1-11).

Ghosh, A., \& Chasey, A. (2013). Structuring data needs for effective integration of building information modeling (BIM) with healthcare facilities management. In 7th International Structural Engineering and

Hedges, K. E., \& Denzer, A. S. (2007). From Integrated Practice to Integrated Academics: BIM in the Classroom. In DCA 20th Anniversary Conference Proceedings (pp. 135-146). Muncie, IN: Ball State University, 2007b.

Jung, W., \& Lee, G. (2015). The status of BIM adoption on six continents. International Journal of Civil, Environmental, Structural, Construction and Architectural Engineering, 9(5), 444-448.

Smith, D. K., \& Tardif, M. (2009). Building information modeling: a strategic implementation guide for architects, engineers, constructors, and real estate asset managers. John Wiley \& Sons.

Sacks, R., Radosavljevic, M., \& Barak, R. (2010). Requirements for building information modeling based lean production management systems for construction. Automation in construction, 19(5), 641-655.

Seletsky, P. (2006). Questioning the Role of BIM in Architectural education: A CounterViewpoint. AECbytes Viewpoint, 27.

Shen, Z., Jiang, L., Grosskopf, K., \& Berryman, C. (2012). Creating 3D web-based game environment using BIM models for virtual on-site visiting of building HVAC systems. In Construction Research Congress 2012: Construction Challenges in a Flat World (pp. 1212-1221). 
Simon, Madlen., \& Hu, Ming. (2017). Infusing Technology Driven Design Thinking in Architectural Education: Two Case Studies. In 2017 ARCC Annucal Conference

Taiebat, M., \& Ku, K. (2010, April). Industry's Expectations of Construction School Graduates' BIM Skills. In Proceedings of ASC conference, Boston. 